University of Nebraska - Lincoln

DigitalCommons@University of Nebraska - Lincoln

2008

\title{
The influence of acidity on microbial fuel cells containing Shewanella oneidensis
}

\author{
Justin C. Biffinger \\ US Naval Research Laboratory, justin.biffinger@nrl.navy.mil \\ Jeremy Pietron \\ US Naval Research Laboratory \\ Orianna Bretschger \\ University of Southern California \\ Lloyd J. Nadeau \\ Air Force Research Laboratory \\ Glenn R. Johnson \\ Air Force Research Laboratory \\ See next page for additional authors
}

Follow this and additional works at: https://digitalcommons.unl.edu/usnavyresearch

Part of the Operations Research, Systems Engineering and Industrial Engineering Commons

Biffınger, Justin C.; Pietron, Jeremy; Bretschger, Orianna; Nadeau, Lloyd J.; Johnson, Glenn R.; Williams, Cynthia C.; Nealson, Kenneth H.; and Ringeisen, Bradley R., "The influence of acidity on microbial fuel cells containing Shewanella oneidensis" (2008). U.S. Navy Research. 15.

https://digitalcommons.unl.edu/usnavyresearch/15

This Article is brought to you for free and open access by the U.S. Department of Defense at DigitalCommons@University of Nebraska - Lincoln. It has been accepted for inclusion in U.S. Navy Research by an authorized administrator of DigitalCommons@University of Nebraska - Lincoln. 


\section{Authors}

Justin C. Biffinger, Jeremy Pietron, Orianna Bretschger, Lloyd J. Nadeau, Glenn R. Johnson, Cynthia C. Williams, Kenneth H. Nealson, and Bradley R. Ringeisen 


\title{
The influence of acidity on microbial fuel cells containing Shewanella oneidensis
}

\author{
Justin C. Biffinger ${ }^{\mathrm{a}}$, Jeremy Pietron ${ }^{\mathrm{a}}$, Orianna Bretschger ${ }^{\mathrm{b}, \mathrm{d}}$, Lloyd J. Nadeau ${ }^{\mathrm{c}}$, Glenn R. Johnson ${ }^{\mathrm{c}}$, \\ Cynthia C. Williams ${ }^{a}$, Kenneth H. Nealson ${ }^{b}$, Bradley R. Ringeisen ${ }^{a, *}$ \\ a Chemistry Division, US Naval Research Laboratory, 4555 Overlook Avenue, SW, Washington, DC 20375, United States \\ ${ }^{\mathrm{b}}$ Department of Earth Sciences, Mail Code 0740, University of Southern California, Los Angeles, CA 90089-0740, United States \\ c Air Force Research Laboratory, 139 Barnes Drive, Suite \#2, Tyndall AFB, FL 32403, United States \\ d The Mork Family Department of Chemical Engineering and Materials Science, Mail Code 0241, \\ University of Southern California, Los Angeles, CA 90089-0241, United States
}

\section{A R T I C L E I N F O}

\section{Article history:}

Received 12 June 2008

Accepted 17 July 2008

Available online 30 July 2008

\section{Keywords:}

Microbial fuel cells (MFCs)

Acidity

Shewanella oneidensis

Mediated electron transfer

\begin{abstract}
A B S T R A C T
Microbial fuel cells (MFCs) traditionally operate at pH values between 6 and 8. However, the effect of $\mathrm{pH}$ on the growth and electron transfer abilities of Shewanella oneidensis MR-1 (wild-type) and DSP10 (spontaneous mutant), bacteria commonly used in MFCs, to electrodes has not been examined. Miniature MFCs using bare graphite felt electrodes and nanoporous polycarbonate membranes with MR- 1 or DSP10 cultures generated $>8 \mathrm{~W} / \mathrm{m}^{3}$ and $\sim 400 \mu \mathrm{A}$ between $\mathrm{pH}$ 6-7. The DSP10 strain significantly outperformed MR-1 at neutral $\mathrm{pH}$ but underperformed at $\mathrm{pH}$ 5. Higher concentrations of DSP10 were sustained at $\mathrm{pH} 7$ relative to that of MR-1, whereas at $\mathrm{pH} 5$ this trend was reversed indicating that cell count was not solely responsible for the observed differences in current. S. oneidensis MR-1 was determined to be more suitable than DSP10 for MFCs with elevated acidity levels. The concentration of riboflavin in the bacterial cultures was reduced significantly at $\mathrm{pH} 5$ for DSP10, as determined by high performance liquid chromatography (HPLC) of the filter sterilized growth media. In addition, these results suggest that mediator biosynthesis and not solely bacterial concentration plays a significant role in current output from $S$. oneidensis containing MFCs.
\end{abstract}

Published by Elsevier B.V.

\section{Introduction}

Microbial fuel cells (MFCs) are bioelectrochemical devices that are capable of harvesting power directly from the environment (Du et al., 2007; Logan et al., 2006). Because of the mild operating conditions used within MFCs, the microbiology occurring at the anode and eliminating/replacing cation exchange membranes are areas of interest specific to MFC researchers. Improving the oxygen reduction reaction (ORR) at the cathode is a priority for all fuel cell applications, but for MFCs, power generation is often limited specifically by poor cathode performance (Zhao et al., 2006). Increasing the acidity of the catholyte is one parameter that has the potential to greatly improve ORR efficiency but could dramatically decrease bacterial activity at the anode. An increase in acidity will also decrease the resistance of the proton exchange membrane (PEM) commonly used in MFCs. Therefore, it is important

\footnotetext{
* Corresponding author. Tel.: +1 202767 0719; fax: +1 2024048119.

E-mail address: Bradley.ringeisen@nrl.navy.mil (B.R. Ringeisen).
}

to probe how the entire MFC system is affected when operating at lower $\mathrm{pH}$.

Acidity is one of the most important environmental factors impacting bacterial cell growth and physiology (Foster, 2000). Environmental stresses on growth and protein expression for the Shewanella sp. have recently been reported by several groups (Beliaev et al., 2005; Dague et al., 2006; Gaboriaud et al., 2005; Gao et al., 2004; Leaphart et al., 2006), but only an isolated report discusses the effects of acidity on power production from a bacterial consortia within a MFC (Gil et al., 2003). Shewanella oneidensis (originally known as Shewanella putrefaciens) is a nonfermenting, motile, facultative anaerobic bacterium found in suboxic sediments (Perry et al., 1993; Venkateswaran et al., 1999; Venter et al., 2004). Shewanella are well known for the diversity of terminal electron acceptors they can reduce and are one of the primary families of bacteria used in MFCs (Logan et al., 2006). S. oneidensis MR-1 is the wild type strain while S. oneidensis DSP10 is a spontaneous rifampin-resistant mutant that has been used primarily for microbial physiology studies (Gao et al., 2004; Thompson et al., 2002) and more recently used in MFCs (Ringeisen et al., 2006). 
The importance of Shewanella as potential bioelectrochemical catalysts for MFC technology continues to drive research into the adaptability of Shewanella for power production.

Cation exchange membranes (e.g. Nafion ${ }^{\circledR}$ ) function optimally under acidic conditions due to the $\mathrm{p} K_{\mathrm{a}}(<1)$ of the protonated perfluorinated sulfonic acid groups. The effects of acidity on Nafion ${ }^{\circledR}$ within MFCs were recently reported by Hamelers et al., where cations $\left(\mathrm{Na}^{+}, \mathrm{K}^{+}, \mathrm{Ca}^{2+}\right)$ were transported preferentially to protons at neutral $\mathrm{pH}$ because of relative concentrations (Rozendal et al., 2006). Several fuel cell designs have been published recently that decrease the overall internal resistance of the device by eliminating the proton exchange membrane (PEM) entirely (Liu and Logan, 2004; Liu et al., 2004) or replacing the PEM with nanoporous filtration membranes (Biffinger et al., 2007b; Kim et al., 2007) or bipolar membranes (ter Heijne et al., 2006). However, the localized pH gradients established in MFCs by using cation selective membranes under non-optimized conditions complicate the operation of MFCs and decrease their durability (Gil et al., 2003). Thus, freely diffusive nanoporous membranes would eliminate $\mathrm{pH}$ gradients between the cathode and anode chambers and simplify analysis of the anode and cathode electrodes with defined pH changes.

Oxygen is the most desirable terminal electron acceptor in MFCs not only for its high standard reduction potential, but also because of practical considerations for environmental deployment (Wang, 2005). Regardless of the catalyst, the electrochemical effects of acidity on ORR will indirectly affect the working potential range (Spendelow and Wieckowski, 2007) of the MFC. According to the Nernst equation, the potential of ORR should shift $+59 \mathrm{mV}$ for each $\mathrm{pH}$ unit in the acidic direction (i.e. the driving force for the fuel cell reaction increases with decreasing $\mathrm{pH}$ ). Decreasing the overall operational $\mathrm{pH}$ of a MFC from neutral $\mathrm{pH}$ would be a fundamental parameter that could be changed to generate significant increases in current output from MFCs.

In this work, the impact of proton concentration on the anodic and cathodic reactions were analyzed using a miniature MFC. The miniature-MFC (mini-MFC) developed at the Naval Research Laboratory shows promise both as a power source for aerobic environments (Ringeisen et al., 2007) and as a device to evaluate current production from bacteria under a wide variety of aerobic and anaerobic growth conditions (Biffinger et al., 2008). Since the bulk of the MFC volume $(50 \mathrm{~mL})$ is external to the operational volume of the anode chamber (void volume $<500 \mu \mathrm{L}$ ), high bacterial cell counts and a high surface area-to-chamber volume ratio $\left(>500 \mathrm{~cm}^{-1}\right.$ ) enable rapid and efficient shuttling of electrons to the anode surface. This is because oxygen (a superior electron acceptor) is scrubbed quickly from aerobic cultures in the anode chamber and this facet of the mini-MFC has resulted in high power densities per volume $\left(300 \mathrm{~W} / \mathrm{m}^{3}\right)$ from aerated S. oneidensis DSP10 cultures (Ringeisen et al., 2007).

If MFCs are to be used at $\mathrm{pH}$ values below 7, where the cathode potential (via the ORR) is enhanced by increased proton concentration, then the effect of acidity on the metabolism of electrochemically active bacteria (EAB) must be understood. We use the mini-MFC along with nanoporous filter membranes to determine how both the cathodic and anodic reactions change with $\mathrm{pH}$. We demonstrate that both $S$. oneidensis MR-1 and DSP10 can be used in MFCs at proton concentrations as high as $1 \times 10^{-5} \mathrm{M}$ under initially aerobic conditions. However, these Shewanella strains show different tolerances to high proton concentrations, which in turn affect their electron transfer performance at the anode. Not only does $\mathrm{pH}$ modify growth of these strains, but it impacts the presence of electron shuttles (mediators) observed in the growth medium (anolyte). To our knowledge, these studies are the first to investigate the impact of acidity on the growth, metabolism and electron transfer of bacteria in a MFC. By tracking both MFC anode and cath- ode function at different pHs, we gained both fundamental and practical insight into the complex biological, chemical and physical processes that occur during MFC operation.

\section{Materials and methods}

\subsection{Supplies and materials}

Stock solutions of $1.95 \mathrm{M}$ sodium lactate were adjusted to the desired $\mathrm{pH}$ and autoclaved for $15 \mathrm{~min}$ at $121^{\circ} \mathrm{C}$. Luria-Bertani (LB) Broth (Miller) and LB/agar (Difco LB-Agar, Miller) was used for liquid cultures and plates, respectively (Fisher Scientific, Inc.). The LB growth media was dissolved in $50 \mathrm{mM}$ phosphate buffer adjusted to $\mathrm{pH} 5,6$, or 7 with $\mathrm{HCl}$. The formulation of minimal growth medium (MM) was reported previously (Myers and Nealson, 1988) and was used during electrochemical experiments to isolate the redox behavior of the mediator.

\subsection{Cell culture conditions}

S. oneidensis MR-1 and DSP10 were grown from $-80^{\circ} \mathrm{C}$ glycerol stock cultures by inoculating $50 \mathrm{~mL}$ of LB broth with gentle shaking ( $100 \mathrm{rpm}$ ) for approximately $70 \mathrm{~h}$ before assembling the mini-MFC experiment. Cultures used in MFC experiments were from three sub-cultures removed from the original frozen stock culture. S. oneidensis cultures of MR-1 and DSP10 for these fuel cell experiments were inoculated from the same stock cultures to assure there was parity in the MFC results. Doubling time for S. oneidensis MR-1 growth at $\mathrm{pH} 7$ was calculated during exponential growth phase.

\subsection{Miniature microbial fuel cell (mini-MFC) assembly and operation}

The general dimensions and setup of the mini-MFC were published previously (Ringeisen et al., 2006) and a diagram of the overall setup is provided in Supplementary Fig. S1. The design of the mini-MFC optimizes the ratio of electrode surface area to chamber volume and in turn generates high power density $\left(500 \mathrm{~W} / \mathrm{m}^{3}\right)$ per volume with aerobic fuel supplies and S. oneidensis DSP10 (Biffinger et al., 2008; Ringeisen et al., 2006). The membrane for the experiments presented here was a freely diffusive $0.2 \mu \mathrm{m}$ polycarbonate membrane (Poretics Corp.). Unless designated in the text, the cathodic ORR was catalyzed by unmodified graphite felt (GF) electrodes $\left(0.13 \mathrm{~g}\right.$, approximately $500 \mathrm{~cm}^{-1}$ in the $1.2 \mathrm{~cm}^{3}$ chamber). In specified cases, graphite felt cathodes coated with Pt nanoparticles (Pt-GF) were used (Supplementary materials).

The anode electrode was also unmodified graphite felt $(0.13 \mathrm{~g})$ connected with titanium wire. The flow within the mini-MFC was maintained using a peristaltic pump at $1-2 \mathrm{~mL} / \mathrm{min}$ for the duration of the experiments at $22^{\circ} \mathrm{C}$. The $\mathrm{pH}$ within the anode and cathode chambers was monitored periodically with a basic PerpHect LogR pH meter (Thermo Electron Corp.) and combination electrode. Aliquots of the anode cultures were periodically removed $(1 \mathrm{~mL})$ and filter sterilized with a $0.45 \mu \mathrm{m}$ PTFE filter to monitor the $\mathrm{pH}$ of the acelluar growth media. The electrode potentials versus the $\mathrm{Ag} / \mathrm{AgCl}$ reference electrode (Analytical Sensors, Inc.) were measured at open circuit using an ORION 330 electrochemical apparatus (Thermo Electron Corp.). All MFC experiments were performed in triplicate.

\subsection{Data acquisition}

The voltage across a load was measured by a personal data acquisition device ( $\mathrm{I} / \mathrm{O}$ tech, personal daq/54) every $2 \mathrm{~min}$ as 
was described previously (Ringeisen et al., 2006). Voltage measurements for power curves were allowed to reach steady state $(\sim 5 \mathrm{~min})$. Power measurements were performed in triplicate and the average value was used.

\subsection{Electrochemistry in minimal growth media (MM)}

Four-day-old cultures of MR-1 and DSP10 were subcultured in minimal media (at least three times) and allowed to grow for 3 days each time. These Shewanella subcultures were then centrifuged for $5 \mathrm{~min}\left(8.6 \mathrm{~kg}, 15^{\circ} \mathrm{C}\right)$ and filtered with a $0.2 \mu \mathrm{m}$ PTFE filter for electrochemical analysis. In a three-electrode electrochemical cell, a 5-mm diameter polished glassy carbon electrode was used as the working electrode, a gold wire was used as the counter electrode and an $\mathrm{Ag} / \mathrm{AgCl}$ reference electrode (Bioanalytical Systems) completed the electrochemical cell. The MM culture supernatants were continuously sparged with argon to maintain anoxic conditions during electrochemical measurements. The working electrode was polished before each measurement using an aqueous slurry of $0.05 \mu \mathrm{m}$ alumina powder (Buehler) on a polishing cloth. Scan rates were $100 \mathrm{mV} / \mathrm{s}$.

\subsection{S. oneidensis growth characteristics between $\mathrm{pH}$ 5-7}

Standard growth curves were obtained by turbidity measurements using a Spectronic 20 with standardized turbidity plots for both MR-1 and DSP10 at pH 5, 6, 7 to equate cell count (determined by plating after serial dilution on LB/Agar plates at $30^{\circ} \mathrm{C}$ ) with absorbance (Supplementary Fig. S2-S7). Error for each cell count measurement was $<7 \%$. The standardization cultures and growth cultures ( $80 \mathrm{~mL}$ each) were all inoculated with $2 \mathrm{~mL}$ of a stock subculture of bacteria in parallel. The cultures were grown in $125 \mathrm{~mL}$ baffled shaker flasks $\left(100 \mathrm{rpm}\right.$ at $\left.25^{\circ} \mathrm{C}\right)$.

\subsection{High performance liquid chromatography (HPLC) analysis of LB growth media}

HPLC analysis of culture broths were performed using Agilent (1100 series) chromatography components (Santa Clara, Calif.) including quaternary pump for mobile phase delivery and diode array detector (DAD) for monitoring eluent and collecting UV-vis spectra. The chromatography column used was an Altima Phenyl ( $250 \mathrm{~mm} \times 4.6 \mathrm{~mm}, 5 \mu \mathrm{m}$ support) (Alltech Assoc., Deerfield Ill). The mobile phase was formic acid:methanol (70:30, $1 \mathrm{~mL} / \mathrm{min})$. The eluent was monitored at $210 \mathrm{~nm}$ and absorbance was recorded (Fig. S11). Culture supernatants were prepared using centrifugation to remove bacteria and insoluble material. Following centrifugation, samples were either analyzed directly using HPLC or concentrated using solid phase extraction (SPE) cartridge. For SPE, $5 \mathrm{~mL}$ of culture supernatant were passed through $100 \mathrm{mg}$ of preconditioned $\mathrm{C}_{18}$ resin (Suplelco, Bellefonte, Penn). Polar compounds were washed from the matrix with an equal volume of water and then the non-polar molecules eluted with $0.5 \mathrm{~mL}$ methanol. The concentrated samples were analyzed using HPLC as described above.

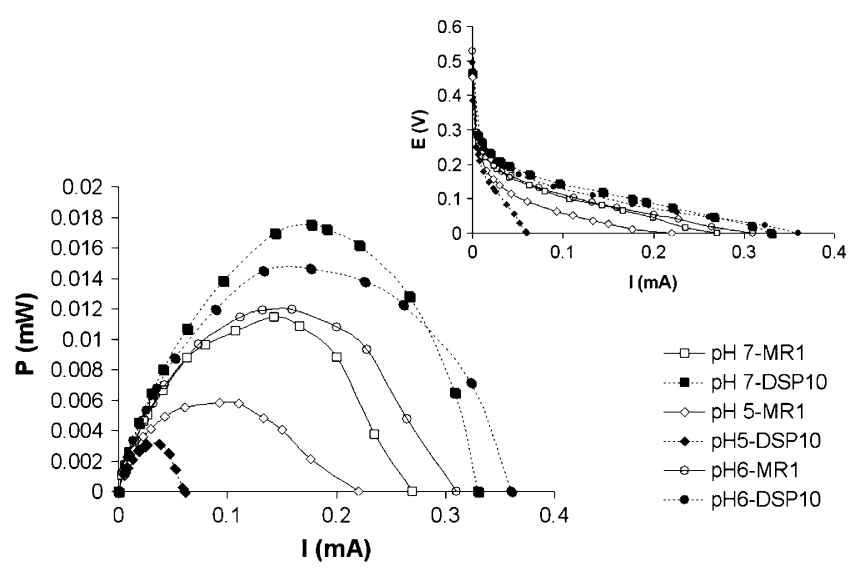

Fig. 1. Power and polarization curves for mini-MFCs containing Shewanella oneidensis MR1 or S. oneidensis DSP10 at pH 5, pH 6, and pH 7 in both the cathode and anode.

\section{Results and discussion}

\subsection{The influence of $\mathrm{pH}$ on power production by S. oneidensis}

The mini-MFCs at pH 5, 6, and 7 were monitored for at least $100+\mathrm{h}$ (data not shown) with sodium lactate ( $10 \mathrm{mM}$ additions) as the carbon food source. The use of polycarbonate membranes resulted in negligible change in $\mathrm{pH}$ in either the anode or cathode chambers during the course of mini-MFC operation. A significant change in $\mathrm{pH}$ is commonly observed when using a Nafion ${ }^{\circledR}$ membrane (Gil et al., 2003; Zhao et al., 2006) but free diffusion through the membrane eliminates these $\mathrm{pH}$ gradients. The power curves for each fuel cell are provided in Fig. 1 with polarization curves (voltage versus current) shown in the inset for both MR-1 and DSP10. The MFC data from both MR-1 and DSP10 are summarized in Table 1. Mini-MFCs containing DSP10 exhibited the same general trend as for MR-1. Slightly higher power densities of $14 \mathrm{~W} / \mathrm{m}^{3}$ and $12 \mathrm{~W} / \mathrm{m}^{3}$ for DSP10 were recorded at $\mathrm{pH} 7$ and 6 compared to the values of $9.2 \mathrm{~W} / \mathrm{m}^{3}$ and $10 \mathrm{~W} / \mathrm{m}^{3}$, respectively, measured for MR-1. MiniMFCs operated at $\mathrm{pH} 7$ and 6 generated between 20 and $50 \%$ higher power output and maximum current values for DSP10 than measured for MR-1 (Table 1$)$. The impact of elevated acidity stress $(<\mathrm{pH}$ 6 ) on the functioning system is clearly observed by significantly less power from DSP10 (3.0 W/m³ $\mathrm{m}^{3}$, Fig. 1, closed diamonds) than MR-1 $\left(6.0 \mathrm{~W} / \mathrm{m}^{3}\right.$, Fig. 1 , open diamonds) and $30 \%$ less current under short circuit at $\mathrm{pH} 5$.

In order to isolate the effect solution acidity has on either the anodic or cathodic reactions, the average open circuit voltages and cathode or anode potentials were monitored versus a $\mathrm{Ag} / \mathrm{AgCl}$ reference electrode (Fig. 2). First, there was no variation of open circuit potentials of all fuel cells with changing $\mathrm{pH}$ (Fig. 2, left panel). Secondly, as predicted from the Nernst equation, changing the $\mathrm{pH}$ from 7 to 6 shifted the cathode potential $+61 \pm 3 \mathrm{mV}$ versus SCE. However, the cathode potential shift was negligible from $\mathrm{pH} 6$ to 5 ; this is most likely due to a low concentration of catalytic sites on bare

Table 1

Electrical parameters from mini-MFC containing Shewanella oneidensis MR-1 and DSP10

\begin{tabular}{|c|c|c|c|c|c|c|}
\hline \multirow[t]{2}{*}{$\mathrm{pH}$} & \multicolumn{3}{|l|}{ DSP10 } & \multicolumn{3}{|l|}{ MR-1 } \\
\hline & $\mathrm{OCV}(\mathrm{V})$ & $I_{\mathrm{sc}}(\mathrm{mA})$ & Power density $\left(\mathrm{W} / \mathrm{m}^{3}\right)$ & $\mathrm{OCV}(\mathrm{V})$ & $I_{\mathrm{sc}}(\mathrm{mA})$ & Power density $\left(\mathrm{W} / \mathrm{m}^{3}\right)$ \\
\hline 5 & 390 & $0.06 \pm 0.02$ & $3.0 \pm 1$ & 450 & $0.22 \pm 0.03$ & $6.0 \pm 1$ \\
\hline 6 & 490 & $0.36 \pm 0.03$ & $12 \pm 1$ & 530 & $0.31 \pm 0.03$ & $10 \pm 1$ \\
\hline 7 & 460 & $0.33 \pm 0.05$ & $14 \pm 2$ & 470 & $0.27 \pm 0.02$ & $9.2 \pm 2$ \\
\hline
\end{tabular}

$I_{\mathrm{sc}}$ : short circuit current; OCV: open circuit voltage. 

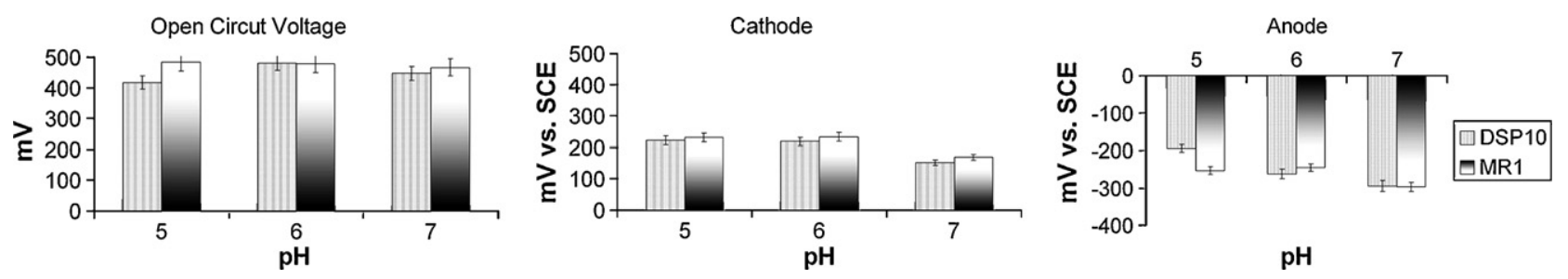

Fig. 2. Microbial fuel cell half cell potentials versus $\mathrm{Ag} / \mathrm{AgCl}$ at $\mathrm{pH} 5, \mathrm{pH} 6, \mathrm{pH} 7$.

carbon for the ORR and limited oxygen adsorption, muting the effect of increased proton concentration. Finally, the anode potentials for all bacteria becomes more positive (decreasing the overall cell potential) when the $\mathrm{pH}$ was decreased from $\mathrm{pH} 7$ to $\mathrm{pH} 5$. However, the anode potential for MR- 1 at pH 5 was significantly less diminished and remained $59 \pm 1 \mathrm{mV}$ cathodically shifted from an anode with DSP10.

The effect of $\mathrm{pH}$ on the anode compartment was recently reported by Gil et al., in a study probing $\mathrm{pH}$, electrolyte, resistance, and oxygen content in MFCs (Gil et al., 2003). Their work determined that MFC performance was most efficient between $\mathrm{pH} 7$ and 8 for a microbial consortium cultured over 3 years. Their results also suggest that microbial activity diminished at sub-optimal $\mathrm{pH}$ values in their MFC. We find that solution acidity affected S. oneidensis in distinctly different ways. Specifically, we observed that current output was impacted not only by bacterial cell count but also by changes in the amount of autologous redox active mediators in the growth media at lower pH values (see Section 3.3.2).

\subsection{Catalysis of oxygen reduction with graphite electrodes}

Graphite catalyzes the two electron reduction of oxygen to hydrogen peroxide preferentially (Yeager, 1984). In the work presented here, the $59 \mathrm{mV}$ anodic shift in cathode redox potential was negated below $\mathrm{pH} 6$. The cathode potential versus $\mathrm{Ag} / \mathrm{AgCl}$ at $\mathrm{pH}$ 5 remained unchanged (Fig. 2, cathode chart). Therefore, the differences in power output at pH 5 between MR-1 and DSP10 were due to changes in the anode chamber rather than $\mathrm{pH}$-enhanced ORR catalysis on the unmodified GF cathode. In contrast to unmodified GF, the rate of ORR significantly increased in our experiments when Pt was deposited on graphite felt cathodes (Supplementary Fig. S8). The power curves for these mini-MFC experiments exhibited a much larger increase with decreasing $\mathrm{pH}$ than the unmodified GF experiments presented earlier (Fig. 1) and can be attributed to the higher catalytic activity of platinum for oxygen reduction.

\subsection{Factors affecting power output from MFCs containing $S$. oneidensis at $\mathrm{pH} 5,6$, and 7}

The differences observed in power production as a function of $\mathrm{pH}$ may be explained in a number of ways, two of which are considered below.

\subsubsection{Changes in growth of S. oneidensis $M R-1$ or DSP10}

One explanation for the differences in current production could be that there are different numbers of cells present: i.e. that growth at different $\mathrm{pH}$ values yields different numbers of viable cells. If the yield of viable $S$. oneidensis cells changed as a function of $\mathrm{pH}$, it could affect the power output (lower cell counts could yield lower fuel cell current output) from the mini-MFC. To test this hypothesis, S. oneidensis was grown in LB adjusted to the desired $\mathrm{pH}$ with a $50 \mathrm{mM}$ phosphate buffer. The growth of each culture was monitored over several hours into the stationary phase of bacterial growth (Fig. 3). The lag times for all experiments were $<25 \mathrm{~h}$ after the initial inoculation, and the $\mathrm{pH}$ of the cultures was unchanged throughout the experiment.

MR-1 grew to a maximum cell concentration of $>2 \times 10^{8} \mathrm{CFU} / \mathrm{mL}$ after $35 \mathrm{~h}$ of growth at $\mathrm{pH} 6$ and 5 , and to only $8 \times 10^{7} \mathrm{CFU} / \mathrm{mL}$ at $\mathrm{pH}$ 7. In contrast, DSP10 showed the highest cell concentration at pH 6 and 7, and was significantly lower at pH 5 where the concentration was only $5 \times 10^{7} \mathrm{CFU} / \mathrm{mL}$, while MR- 1 was 10 times greater. The lowest concentration of cells was recorded at $\mathrm{pH} 7$ for MR-1 $\left(7 \times 10^{7} \mathrm{CFU} / \mathrm{mL}\right)$ and $\mathrm{pH} 5$ for DSP10 $\left(8 \times 10^{7} \mathrm{CFU} / \mathrm{mL}\right)$. Doubling times calculated from our experiments at $\mathrm{pH} 7$ for MR-1 ( $\sim 38 \mathrm{~min}$ ) are similar to results reported in a recent publication analyzing doubling times for MR-1 at low temperatures ( $\sim 45 \mathrm{~min}$ ) (Abboud et al., 2005).

S. oneidensis MR-1 and DSP10 have been considered essentially interchangeable for both genetic and bioremediation research projects. However, comparison between power production by $S$. oneidensis MR-1 and DSP10 within a MFC have not been reported in the literature. The power density at neutral $\mathrm{pH}$ was significantly higher for DSP10 in the mini-MFC than MR-1 (30\% greater, Table 1). At pH 5, distinctly higher short circuit current and power (Fig. 1) were generated by MR-1 versus that for DSP10 (Table 1). Differential biofilm formation could be an explanation for these power and current differences considering electron transfer from Shewanella to an electrode surface may require significant bacterial attachment to the surface (Stams et al., 2006). However, our previous mini-MFC experiments suggest that power output is independent of the fraction of biofilm coverage when using stationary phase, planktonic $S$. oneidensis cultures at a concentration of $10^{8} \mathrm{CFU} / \mathrm{mL}$ (Ringeisen et al., 2006). This conclusion was supported by the consistent power response to various lactate concentrations with $10^{8} \mathrm{CFU} / \mathrm{mL}$ DSP10 cultures in LB when compared to experiments designed to form active biofilms using minimal media (Biffinger et al., 2007a). The biofilm experiments showed concentration-dependent responses to lactate, but similar total power output to mini-MFCs with minimal biofilm coverage and $10^{8} \mathrm{CFU} / \mathrm{mL}$ culture anolytes. Because we are using stationary phase, planktonic cultures for the experiments

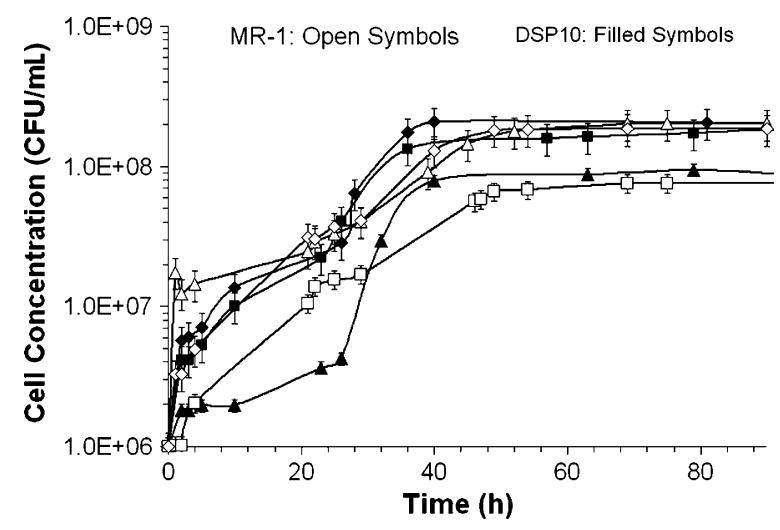

Fig. 3. Growth characteristics in LB for S. oneidensis DSP10 and S. oneidensis MR-1 at pH 5, pH 6, and pH 7. Triangles: $\mathrm{pH} 7$; diamonds: $\mathrm{pH}$ 6; squares: $\mathrm{pH} 5$. 


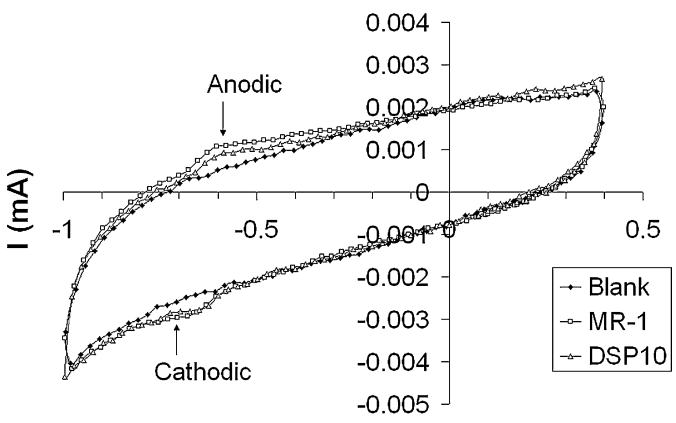

$E$ (V) vs. $\mathrm{Ag} / \mathrm{AgCl}$

Fig. 4. Cyclic voltammetry of filter sterilized media after 4 days of growth of $S$. oneidensis MR-1 or S. oneidensis DSP10 in minimal media at pH 7 (A) or in LB at pH 5 (B) or $\mathrm{pH} 7$ (C).

presented here, differential biofilm coverage was not a significant factor impacting the observed current and power discrepancies.

Correlation between bacterial cell count and power output can be derived from the amount of current (or coulombs per second) produced by each bacterium. In general, the data presented in Fig. 1 shows that current is directly proportional to cell count (Fig. 3) except for DSP10 at $\mathrm{pH} 5$. The $\mathrm{CFU} / \mathrm{mL}$ for MR- 1 at $\mathrm{pH} 7$ is similar to DSP10 at pH $5\left(7 \pm 1 \times 10^{7} \mathrm{CFU} / \mathrm{mL}\right)$. However, the maximum current produced by MR- 1 at $\mathrm{pH} 7(0.22 \pm 0.03 \mathrm{~mA})$ is five times larger than for DSP10 at pH $5(0.06 \pm 0.02 \mathrm{~mA})$ at short circuit. This indicates that $\mathrm{CFU} / \mathrm{mL}$ cannot account for all the differences in power and current output observed in Fig. 1. These results demonstrate that DSP10 is more sensitive to $\mathrm{pH}$ than MR-1. Additionally, it appears that there is an uncoupling of growth and current production in MR-1, such that low density cultures of MR-1 ( $\mathrm{pH} 7$ ) are capable of similar current output to higher density cultures $(\mathrm{pH} 5$, $6)$.

\subsubsection{Shewanella physiological response to acidity}

Shewanella sp. play a critical role in environmental biological metal oxide reduction; it is known that much of the activity of metal oxide-reducing bacteria occurs at the outer membrane (Bretschger et al., 2008; Thompson et al., 2002). However, the effects of $\mathrm{pH}$ on $S$. oneidensis are relatively uncharted. Changes in cellular physiology and gene expression have been explored by physical (atomic force microscopy (AFM), transmission electron microscopy (TEM), microelectrophoresis) and microbiological methods (microarray analysis (Leaphart et al., 2006)). The physical method reported by Gaboriaud et al., concluded that the polymeric outer membrane of Shewanella swells and softens as the $\mathrm{pH}$ is increased from 4 to
10 and demonstrates how experimental conditions can drastically effect bacterial adhesion and physiology (Gaboriaud et al., 2006). This softening also changes the electrophoretic transport rates of particles through the membrane (Dague et al., 2006) which will affect the rate of the electron transfer through the membrane and ultimately decrease power production at higher $\mathrm{pH}$. Considering Shewanella may biosynthesize mediators to aid in electron transfer to metal surfaces, the role acidity plays on autologous mediator concentration could be quite pronounced.

Additional experiments were performed to determine how Shewanella responded physically to acid stress. Several reports have been published about the potential secretion of mediators (menaquinones, ubiquinone, etc.) by Shewanella (Newman and Kolter, 2000; Ward et al., 2004), but there are conflicting hypotheses as to how the mediators leave the cells. Specifically, it is unknown whether cells actively secrete these redox active molecules into the growth medium or whether cell death and subsequent lysing is the predominant mechanism (Lies et al., 2005). Additionally, there are no reports of how the presence of autologous mediators in the growth medium changes with $\mathrm{pH}$. We analyzed filter sterilized culture supernatants by cyclic voltammetry (Fig. 4), and HPLC (Fig. 5) from DSP10 and MR-1 cultures at pH 5 and 7 and found evidence of differential concentrations of riboflavin. The presence of riboflavin and its role as an extracellular electron shuttle for Shewanella was first reported by von Canstein et al.(2008) and further characterized by Bond and co-workers (Marsili et al., 2008).

Cyclic voltammetry was used to detect redox-active compounds in growth media supernatants from MR-1 and DSP10 cultures. Fig. 4 shows cyclic voltammetry performed on minimal growth media at pH 7 (Myers and Nealson, 1988), including a blank sample that had not been exposed to Shewanella, and one in which each bacterium was cultured at $\mathrm{pH}$ 7. Both MR-1 and DSP10 growth media showed a single cathodic peak at $(-650 \mathrm{mV}$ (arrows)) and anodic peak $(-590 \mathrm{mV})$ at $\mathrm{pH}$ 7. These features are completely absent in the blank minimal media voltammetry and indicate the presence of autologous redox-active compounds in the Shewanella growth medium but cannot be exclusively assigned to riboflavin.

The influence of these different culture environments on S. oneidensis was not only observable by CV but also by HPLC (Fig. 5). Comparison of the culture supernatants and the LB medium using HPLC revealed a peak that eluted at approximately 8-min in only post-culture supernatants. The apparent concentration of the 8min peak in culture supernatants was limited and diode array detection (DAD) spectroscopy showed few distinct spectral features. In order to better characterize the compound, supernatant samples were concentrated using solid phase preparative chromatography and re-analyzed. The preparative chromatography
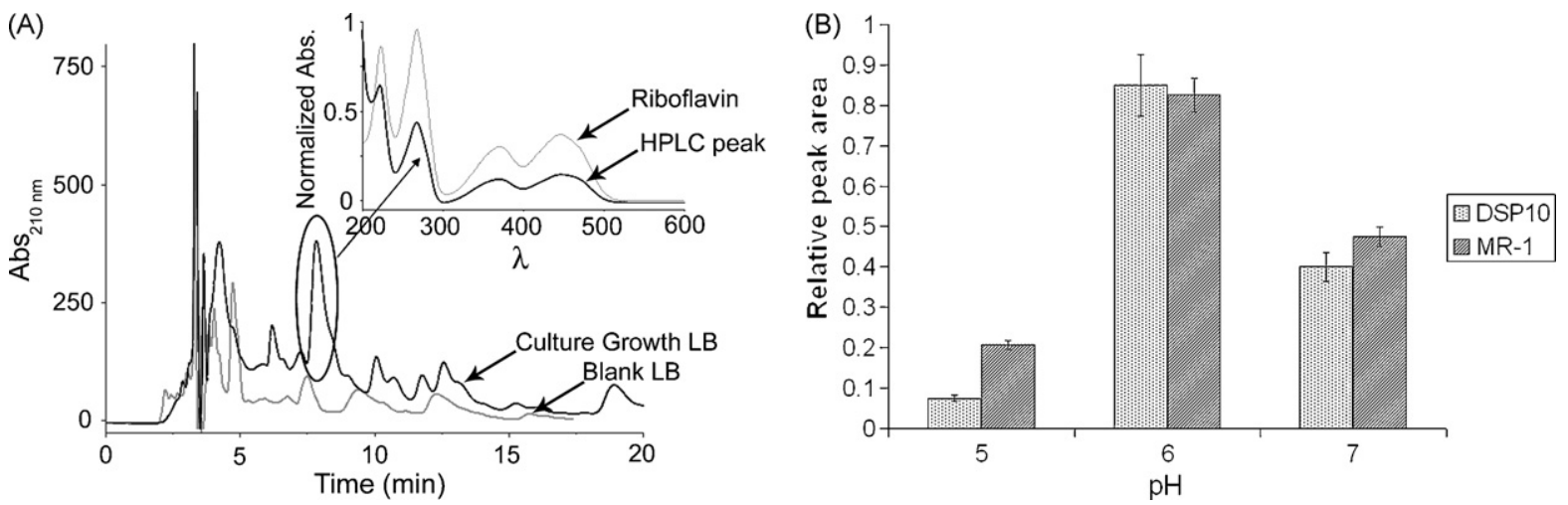

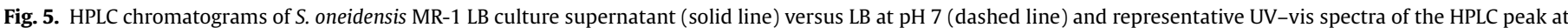
$8 \mathrm{~min}$ (inset: solid line) versus riboflavin (inset: dashed line). 
resin trapped an intense orange fraction from culture supernatants. No evidence of similar compounds was shown in extracts from stock LB. Subsequent HPLC separation of the preparation and UV-vis spectroscopy of the collected compounds revealed that the 8 -min peak showed absorbance maxima at 222, 268, 370 and $448 \mathrm{~nm}$. Further comparison to a riboflavin standard showed that the compound co-elutes with riboflavin and the UV-vis spectra of the product from culture supernatants and riboflavin share identical features (Fig. 5A, inset). These data suggest that riboflavin is present in $S$. oneidensis culture supernatants.

Data obtained during HPLC experiments was used to quantify the relative amount of riboflavin at pH 5 or 7 for MR-1 and DSP10 (Fig. 5B). Relative riboflavin concentrations were calculated from HPLC peak areas, and these data showed consistent correlations with the mini-MFC results presented above (Fig. 1). Comparison of MR-1 and DSP10 mediator concentrations showed that at $\mathrm{pH}$ 7, the concentration of mediator was equivalent but at pH 5 MR- 1 had $>70 \%$ more mediator present. This difference in concentration certainly accounts for the increased current for MR- 1 at $\mathrm{pH} 5$ and shows the impact proton concentrations plays on mediator expression for Shewanella. However, further experiments are being performed to confirm that riboflavin is the only redox active molecule unique to growth culture used by Shewanella at varying acidities. Decaheme c-type cytochromes are another redox active component recently characterized by Hartshorne et al., that could also play a role in mediating electron transfer to metal oxide surfaces (Hartshorne et al., 2007) but these cytochromes have not been identified from our experiments to date.

\section{Conclusions}

The operational acidity of MFCs has pronounced influence on both bacterial metabolism as well as cathodic ORR rates. Increasing the acidity of MFCs will increase the driving force for cathodic oxygen reduction by $59 \mathrm{mV} / \mathrm{pH}$ unit as long as catalytic activity remains high. Acidity plays an entirely different role on bacterial metabolism. Increasing the acidity of the $S$. oneidensis culture increases the current output from MR-1 compared to DSP10 at pH 5 . This was due to an increase in the presence of redox active mediators (including riboflavin) for MR-1 at pH 5 and DSP10 at pH 7. Even though work with DSP10 has been limited to laboratory settings, this mutant continues to exhibit new and interesting differences with MR-1 that require further study. The results presented in this manuscript are the first experimental evidence that changes in the biosynthesis of redox active compounds by $S$. oneidensis occurs in response to varying proton concentrations, and that this effect, rather than cell concentration, appears to dominate the current and power output of mini-MFCs.

\section{Acknowledgements}

This work was funded by the Office of Naval Research (NRL 6.2 Program Element Number 62123N), the Air Force Office of Scientific Research (MURI program, Award No. FA9550-06-1-0292) and the AFRL research was funded by the US Air Force Research Laboratory, Materials Science Directorate (AFRL-RX). JCB thanks the National Research Council for his postdoctoral research associateship.

\section{Appendix A. Supplementary data}

Supplementary data associated with this article can be found, in the online version, at doi:10.1016/j.bios.2008.07.034.

\section{References}

Abboud, R., Popa, R., et al., 2005. Appl. Environ. Microbiol. 71 (2), 811-816. Beliaev, A.S., Klingeman, D.M., et al., 2005. J. Bacteriol. 187 (20), 7138-7145. Biffinger, J.C., Byrd, J.N., et al., 2008. Biosens. Bioelectron. 23 (6), 820-826. Biffinger, J.C., Pietron, J., et al., 2007a. Biosens. Bioelectron. 22 (8), 1672-1679. Biffinger, J.C., Ray, R., et al., 2007b. Environ. Sci. Technol. 41 (4), 1444-1449. Bretschger, O., Obraztsova, A., et al., 2008. Appl. Environ. Microbiol. 74 (2), 553. Dague, E., Duval, J., et al., 2006. Biophys. J. 90 (7), 2612-2621. Du, Z., Li, H., et al., 2007. Biotechnol. Adv. 25 (5), 464-482.

Foster, J.W., 2000. Bacterial Stress Responses, pp. 99-115.

Gaboriaud, F., Bailet, S., et al., 2005. J. Bacteriol. 187 (11), 3864-3868.

Gaboriaud, F., Dague, E., et al., 2006. Colloids Surf. B: Biointerfaces 52 (2), 108-116. Gao, H., Wang, Y., et al., 2004. J. Bacteriol. 186 (22), 7796-7803.

Gil, G.-C., Chang, I.-S., et al., 2003. Biosens. Bioelectron. 18 (4), 327-334.

Hartshorne, R.S., Jepson, B.N., et al., 2007. JBIC, J. Biol. Inorg. Chem. 12 (7), 1083-1094. Kim, J.R., Cheng, S., et al., 2007. Environ. Sci. Technol. 41 (3), 1004-1009.

Leaphart, A.B., Thompson, D.K., et al., 2006. J. Bacteriol. 188 (4), 1633-1642.

Lies, D.P., Hernandez, M.E., et al., 2005. Appl. Environ. Microbiol. 71 (8), 4414-4426. Liu, H., Logan, B.E., 2004. Environ. Sci. Technol. 38 (14), 4040-4046.

Liu, H., Ramnarayanan, R., et al., 2004. Environ. Sci. Technol. 38 (7), 2281-2285.

Logan, B.E., Hamelers, B., et al., 2006. Environ. Sci. Technol. 40 (17), 5181-5192.

Marsili, E., Baron, D.B., et al., 2008. Proc. Natl. Acad. Sci. U.S.A. 105 (10), 3968-3973. Myers, C.R., Nealson, K.H., 1988. Science (Washington, DC) 240 (4857), 1319-1321.

Newman, D.K., Kolter, R., 2000. Nature (London) 405 (6782), 94-97.

Perry, K.A., Kostka, J.E., et al., 1993. Science (Washington, DC, 1883) 259 (5096), 801-803.

Ringeisen, B.R., Henderson, E., et al., 2006. Environ. Sci. Technol. 40 (8), 2629-2634. Ringeisen, B.R., Ray, R., et al., 2007. J. Power Sources 165 (2), 591-597.

Rozendal, R.A., Hamelers, H.V.M., et al., 2006. Environ. Sci. Technol. 40 (17), 5206-5211.

Spendelow, J.S., Wieckowski, A., 2007. Phys. Chem. Chem. Phys. 9, 2654-2675.

Stams, A.J.M., de Bok, F.A.M., et al., 2006. Environ. Microbiol. 8 (3), 371-382.

ter Heijne, A., Hamelers, H.V.M., et al., 2006. Environ. Sci. Technol. 40 (17), 5200-5205.

Thompson, D.K., Beliaev, A.S., et al., 2002. Appl. Environ. Microbiol. 68 (2), $881-892$.

Venkateswaran, K., Moser, D.P., et al., 1999. Int. J. Syst. Bacteriol. 49 (2), 705-724.

Venter, J.C., Remington, K., et al., 2004. Science (Washington, DC) 304 (5667), 66-74. von Canstein, H., Ogawa, J., et al., 2008. Appl. Environ. Microbiol. 74 (3), 615-623.

Wang, B., 2005. J. Power Sources 152, 1-15.

Ward, M.J., Fu, Q.S., et al., 2004. Appl. Microbiol. Biotechnol. 63 (5), 571-577.

Yeager, E., 1984. Electrochim. Acta 29 (11), 1527-1637.

Zhao, F., Harnisch, F., et al., 2006. Environ. Sci. Technol. 40 (17), 5193-5199. 